\title{
Creative Problem Solving Methods in Education Field and Compare Classic and Matrix 2003
}

\author{
Nebojša Stefanović ${ }^{1}$, Radivoje Mitrović ${ }^{2}$, Predrag Popović ${ }^{3, *}$ \\ ${ }^{1}$ Department for Information and technology science, Information technology school, Belgrade, Serbia \\ ${ }^{2}$ Department for Design in Mechanical Engineering, Faculty of Mechanical Engineering, Belgrade University, Belgrade, Serbia \\ ${ }^{3}$ Vinca Institute of Nuclear Sciences, Bureau for certification, Belgrade, Serbia
}

Email address:

biro@vinca.rs (P. Popović)

${ }^{*}$ Corresponding author

\section{To cite this article:}

Nebojša Stefanović, Radivoje Mitrović, Predrag Popović. Creative Problem Solving Methods in Education Field and Compare Classic and Matrix 2003. Science Journal of Education. Vol. 4, No. 5, 2016, pp. 135-144. doi: 10.11648/j.sjedu.20160405.11

Received: June 1, 2016; Accepted: June 15, 2016; Published: August 17, 2016

\begin{abstract}
TRIZ - is the method enabling stimulation of creative problem solving by way of using the developed knowledge bases, similar system functioning and contradictions removal. The system of education is one of the most complex social systems, burdened with multiple contradictions. The education system's contradictions comprise wishes of parents versus capabilities of children, wishes of teachers versus educational institution capabilities, etc., so that the need arises for presenting the assembling of educational requirements of the society for improving the level of education, versus writing new educational plans, by way of improved technical resources of the society. Being creative, the TRIZ method is an important part of the technological education program at high schools of professional studies and at faculties in the course of studying. An important link to TRIZ method application in education is envisaging of teachers' perceptions in the education technology, which is the first step towards introducing TRIZ method into the educational plan and program at lower educational levels as well. By updating the classical contradiction matrix, there originated the 2003 matrix which takes into consideration and envisages frequency of innovative principles occurrence, thus rendering a significant progress in TRIZ method developing and application. The paper offers and develops application of new models of education management by way of TRIZ method, by the relocation innovative principles of classical and 2003 contradiction matrixes, with the special contribution of applying creative principles in the field of education.
\end{abstract}

Keywords: Creative Methods, Matrix Contradiction, Matrix 2003, Education, TRIZ

\section{Introduction}

In the previously published work [1] were described innovative solving problem in education field. Now we wanted to expose it in a different context and compare significance innovative principles with the changes that have occurred by relocation in the classical and 2003 contradiction matrixes. Prior to originating of the TRIZ method, a specific problem solution was sought for by instantaneous searching for solution, by testing and rectifying unavoidable errors, which is depicted in Fig. 1. In present-day conditions, it is obvious that such old models, coupled with good practice would function inefficiently in new environments, with significantly increased risks. Constant development of innovative approaches is required in all business activities. In answering the question of how to generate new ideas, new services, new educational model, the present-day answer may be either copy aimlessly or search for the solution and rectify mistakes.

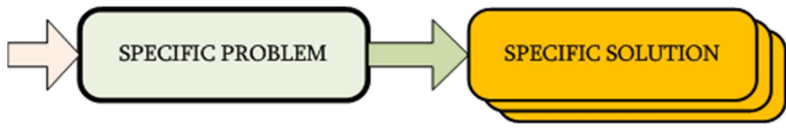

Fig. 1. The classical problem solving approach.

TRIZ research starts with the hypothesis that there are no universal principles of finding a creative solution for each problem. TRIZ represents a problem solving method of 
solving the system safety problem integration based on a set of data obtained from empirical solutions base and from functioning of a similar system. The method utilizes the principle of REPEATABILITY and it was developed by Altshuller [2], [3], [9], who determined that there was a lack of methods for creating new solutions.

In the course of years of its development, the TRIZ problem analysis has incorporated models, innovative principles and effects (Fig. 2)

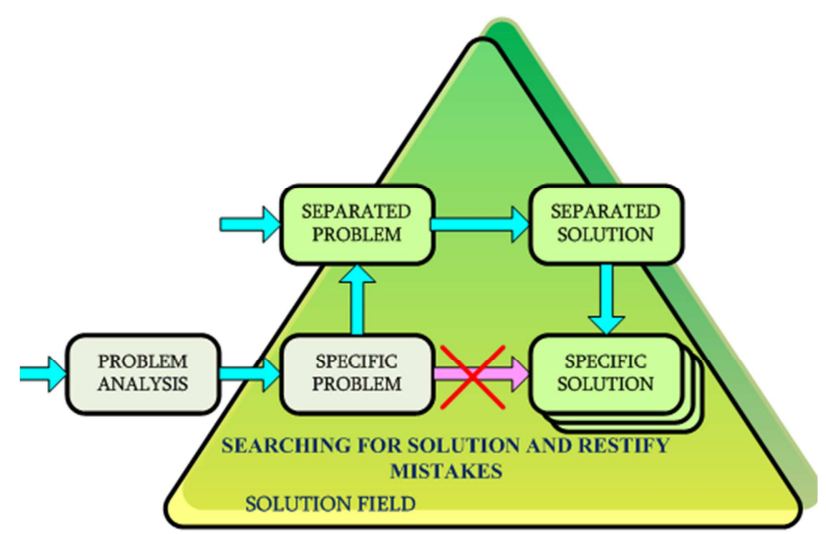

Fig. 2. TRIZ solution models, innovative principles and effects.

The TRIZ method today represents an international way of approaching creativity in resolving the problem of safety integration, which provides results based on discovering causes between problems and the search for solutions. The TRIZ method in the field of Education there are 3 types of identifies contradictions:

1. Physical contradictions,

2. Technical contradictions,

3. Organizational contradictions.

By resolving the organizational contradictions, we reach the situation to have to resolve anew the physical or technical contradictions. The TRIZ method proposes to avoid the exhaustion methods: - by using the contradiction matrixes in resolving the problem of technical contradictions, as well as by changes in the system, in resolving physical contradictions. In analyzing the complex picture and details of an event, TRIZ can have the multiple purposes to check creativity in the educational process and to check creative models. The basis of this method is founded on the following:

a) analysis of regulations in the field of education and

b) reports and experiences in the course of educational cycle.

On the basis of the above stated, various solution structures are made in the process of planning and realizing the educational cycle, so that they need to be taken into consideration as soon as possible. The solutions obtained by the method of compromises in education show applicability of this method's principles. The contradictions matrix implies a set of educational system's features which, individually or in synergy, influence each other in the contradictions affecting productivity as the final measure of the educational system efficiency.

\section{Application TRIZ Method}

TRIZ integrated solutions should inspire, engage and motivate the usage of technological methods in resolving problems in education. Through its innovative modules, the TRIZ method looks for solutions by presenting the next generation of contemporary practice's "products", with the objective of broadening limits and raising standards in the sector of education. TRIZ solutions are expected to enable efficient automatization of all operating procedures and to provide accessibility and knowledge of all the educational process facts by ample information, thus providing a comprehensive counseling display on an integrated platform [3], [4]. Access to the process from any place at any time, represents its fully integrated environment. On the basis of a scientific theory, methods have been developed by studying educational institutions, applying various systems' development patterns, for searching for creative solutions. These methods involve three major components:

- analysis of the logic nature of educational system and its problems,

- application of specific knowledge data bases as the most efficient problem-solving method,

- means for overcoming psychological inertia in the problem-solving process.

- The basic ideas of TRIZ method implementation in education [4] are as follows:

- study on any topic, such as system development,

- relationships between different subjects through educational system evolution patterns,

- application of the problem-solving creative method in lecturing to students,

- creative problem-solving by thematic lecturing by demonstration models,

- mastering the methods for overcoming psychological inertia.

- preserving and strengthening child's innate creative disposition,

- forming of creativity and of vital orientations towards accomplishing goals,

- forming of creative way of thinking,

In order to put it briefly, basic characteristics are stated here, as follows:

1. Flexibility, quick response and fast reaction to the educational system changes,

2. Excellent design in the process implementation,

3. High level of rendered services in the process of educating,

4. Integrated solution of education management through one platform,

5. Reports adjusted to the educational system needs,

6. Easy and comprehensible user environment,

7. Simpler application as compared to other methods,

8. Higher number of options offered for application from higher management level.

TRIZ exploration starts with the hypothesis that there are no universal principles for finding a creative solution for any 
problem based on innovation and advanced technology. If these principles could be identified, task teams would have, in the process of designing, more creativity and they would be capable of predicting much more operative situations.

Creativity today is based on finding a solution and adjusting it to the problem under consideration.

The primary objectives of the TRIZ method research are based on the following facts:

1. problems and their solutions in the field of science are repeatable,

2. samples in technological evolution in the field of science are repeatable, and

3. innovative solutions use scientific effects outside the research field, using the analogy of occurrences and processes.

In developing the method, the knowledge has been arrived at that this method, in the process of planning the educational system behavior, has shown excellent performances regarding speed of analyzing and solution finding. Comparing the method to numerous other methods [5], the knowledge has been arrived at that decisions can be reached by TRIZ method on the basis of seven criteria, as follows:

1. Technique of conditioning/motivating/organizing;

2. Technique based on innovation knowledge;

3. Technique of systematizing;

4. Technique of focusing - concentrating;

5. Technique of hinting;

6. Technique of development management;

7. Technique of coincidence.

The findings of TRIZ method application [3] have shown the following:

- the greatest number of innovative solutions uses the already known solution principle,

- contradictions overcoming brings about an innovative solution as the result,

- innovative solutions are the result of using common patterns,

- the creative problem-solving model is universal for different fields,

The modern TRIZ method, Fig. 3, has also introduced development analyses into the innovative solution search area, system and market analyses, solution behavior forecasts and final assessment of the selected solution (8).

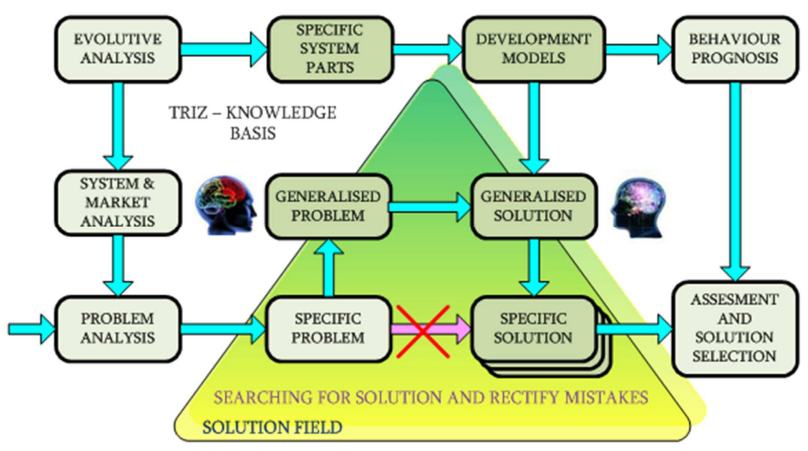

Fig. 3. TRIZ system development.

The arrows show the principle of solution finding according to TRIZ method and the transformational formulating one problem or solution towards another problem. Instead of searching for actual solutions for specific problems, TRIZ proposes getting closer to problems solving at an abstract level. This process comprises problem analysis and analytical usage of empirical data from the existing base.

Being creative, the TRIZ method has for a long time been an important part of the education technology program at specialized departments of high vocational schools and faculties in the course of studying. It is therefore very important to get to see the observation of teachers in education technology, which is the first step towards introducing TRIZ-method into the syllabus and curriculum of even lower levels of education, (11). Creating and realizing TRIZ-workshops will enable using the problem-solving techniques, especially in the education technology.

The workshop trainees were questioned in groups by using written material at the lectures where they were involved into developing the lectures which enticed secondary school pupils to exercise creative thinking. In the later phase, the groups were divided into two independent, mutually opposed entities and questions were raised about their experiences. Divisibility of entities was determined by statistical methods to mutually opposed, and the data were analyzed qualitatively. The questions determined that the benefit of applying TRIZ in education technology was guaranteed.

After this, a workshop was organized lasting for 24 school lessons, where teachers were made familiar with the TRIZ method and its possibilities and effectiveness in education process. After getting familiar with the method history in groups of a few trainees, a lecture unit was developed with identifying TRIZ-method in education, in the following sequence [10]:

- suitability of contradiction usage in education problem solving with secondary school students,

- identifying the parameters present in physical, technical and organizational contradictions of the presented problem,

- technical characteristics necessary for problem solving, and

- final solution

Experience in education of the young has shown that the most important need, which enables the process of educating the young, is creativity which needs managing. There are various levels of creativity, as well as different levels of creative contents in various activities types. The basic conditions for creative work are:

- Presence of uncertainty, i.e. existence of a problem that cannot be solved by known methods,

- Freedom of work by providing instructions with respect to ways, sequence and deadlines,

- Dependence of individual work results on experience, intuition, willpower strength,

- Possibility of competing with others, enabling rising of achievement level.

It is supposed that creativity in performing jobs has got the same role which vitamins play in human health: just a small 
quantity is needed, but without them there occur illnesses and development holdup.

Results of testing the areas into which the TRIZ method of creative problem solving is to be implemented sequentially are as follows: communication technologies, building industry, production and transport (9). It is therefore believed that it would be most appropriate to introduce the TRIZ problem solving method to secondary/grammar schools. As regards the education level at which to start TRIZ training introduction, the first and third years of secondary/grammar schools are recommended as the optimum age level. In order to continue research, it is necessary to introduce TRIZ into education of secondary school students. In the Ministry of Education, Science and Technological Development, there is such initiative, as well as feasibility studies composed by the author.

"Learning should be fun" is the main premise of creative education. In the process of human evolution, the games involving all creativity components were created as the most powerful means for creative education. Games offer to their participants a complex structure composed of adopting various types of knowledge, practical skills and development, psychological and intellectual skills, etc. Games have been oriented towards training and satisfaction of all basic human needs, enabling the young to accept huge amount of information needed for orientation in their environment.
In the last few decades, the educational methods based on games, including also computer games, have become common. All these have been individual trials in the attempt to develop a system of complex education. However, these have got a general shortcoming: the basic element educational methodologies for creative research - is missing. These trials will never become successful without application of TRIZ-education which has to become a unique core, around which all specific methods will be located, [4].

The specific nature of the child's thinking was analyzed. Results of the research were astounding, starting from the analogy between the child's thinking and the TRIZ way of thinking (see Tab. 1), [11]. Comparison of the ways of thinking of grownups, children and TRIZ- method has led to the conclusion, which is still debated today in the field of education, that a healthy child can develop creative capabilities in any field of human activities. Regrettably, these natural observation mechanisms of creative children become almost completely subdued later in life. Only some of them will preserve these in lesser or higher degrees, so that it is not incidental that creative abilities often coincide with infantilism. The main reason for suppressing child's creative abilities is most probably lack of conditions needed for strengthening of these capabilities, as well as the lack of creative stimulation from parents and teachers.

Tab. 1. Comparative table of ways of thinking grown and child.

\begin{tabular}{|c|c|c|}
\hline Grownup thinking & Child thinking & TRIZ thinking \\
\hline $\begin{array}{l}\text { Fear from contradiction, tendency to } \\
\text { avoid explanations in their arguments. }\end{array}$ & $\begin{array}{l}\text { Insensitivity to contradiction, lack of } \\
\text { tendency to avoid explanations in their } \\
\text { arguments }\end{array}$ & $\begin{array}{l}\text { Inclination to contradiction, searching contradiction in problems. } \\
\text { Showing understanding of inventions and formulation of obvious } \\
\text { contradictions both represent a step towards their solving. }\end{array}$ \\
\hline $\begin{array}{l}\text { Metaphysical approach, non-systematic, } \\
\text { separate consideration of subjects, } \\
\text { processes and occurrences. }\end{array}$ & $\begin{array}{l}\text { Grouping of differences; tendency to } \\
\text { connect "everyone with everything". }\end{array}$ & $\begin{array}{l}\text { Systematic approach to problem solving, tendency to discover } \\
\text { connections between remote objects, connections between seemingly } \\
\text { disconnected processes and events. }\end{array}$ \\
\hline $\begin{array}{l}\text { Non-organized combination of various } \\
\text { types of conclusions, applied in the } \\
\text { wrong way. }\end{array}$ & $\begin{array}{l}\text { Transition - drawing conclusions from } \\
\text { wrong point of view according to classical } \\
\text { logic; conclusions based on transferring } \\
\text { single specific problems into another } \\
\text { specific problem. }\end{array}$ & $\begin{array}{l}\text { Drawing conclusions by analogous transfers of ideas; transferring } \\
\text { solutions from one different system of different general level to } \\
\text { another system by combining induction, deduction and transfer. }\end{array}$ \\
\hline $\begin{array}{l}\text { Combination of logic, thinking and } \\
\text { natural intuition }\end{array}$ & $\begin{array}{l}\text { Natural, inherent ability to draw intuitive } \\
\text { conclusions }\end{array}$ & Combination of logical thinking and intention which forms intuition. \\
\hline $\begin{array}{l}\text { Law of obedience - usage of intuitive } \\
\text { knowledge. }\end{array}$ & $\begin{array}{l}\text { Creating laws - spontaneous searching } \\
\text { and intuition development. }\end{array}$ & $\begin{array}{l}\text { Developing laws according to the searching and guiding intuitive } \\
\text { principles }\end{array}$ \\
\hline
\end{tabular}

\section{Conditions for TRIZ Application}

After introducing TRIZ Method into Educational System [1], should be reconsidered Contradiction matrix in education, Tab. 2, [8], and the forty innovative principles has also found application in the field of social human activities. Efforts are made to find a potential solution of the concept generating experiences and knowledge in education by way of the contradiction matrix, according to which this paper represents a theoretical contribution to solving conflicts in the field of education. The descriptions of forty innovative principles and relevant actions have enabled redefining of teaching activities in the field of education, by interpreting educational functions, educational concepts and the terms acquired in the course of the analysis. In the stated example, innovative solutionsactions provide references to various levels of competences in the field of the educational institution's administration, in organizing classroom teaching, or to both areas [8]. The contradiction matrix, Tab. 2, [8] shows mutual influences of contradictory features in educational systems and the innovative principles in education. 
In the contradiction matrix, the fields denoted by (-) indicate that TRIZ principles do not exert mutual influences; for example, universality does not affect the feature of segmentation, homogeneity does not affect asymmetry, etc.

Mutual influences of TRIZ principles is expressed so that in certain fields of the matrix up to four digits can be found, or a matrix field is void when improvement of one TRIZ feature does not affect deterioration of any other TRIZ feature. The contradiction feature shows description of TRIZ principles and of actions necessary for raising the educational system's efficiency. Due to lack of space, this paper presents only the selected principle -3 Local quality, Tab. 3, with description of problem solution searching and of actions which are to be taken.

In that respect, the TRIZ method strives to find a potential solution of the concept generated from experience and knowledge in education by way of a contradiction matrix for the purpose of conflicts solving in the field of elementary and secondary education.

Description of forty innovative principles and adequate actions enables redefining of teaching activities in the field of education by way of interpreting business functions, educational concepts and notions learned in the course of analyzing.

Tab. 2. Contradiction matrix - classical (partial view).

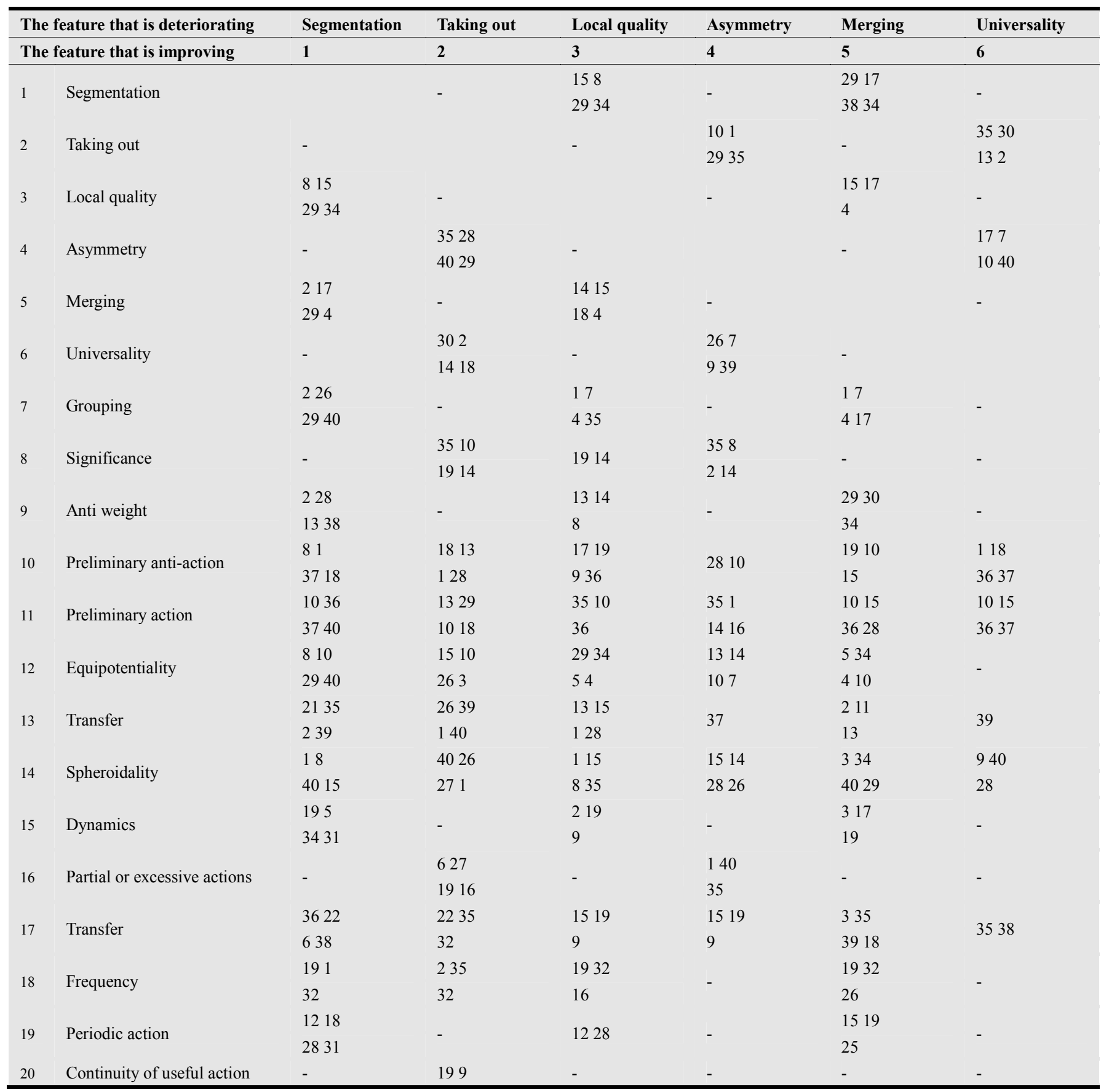


Tab. 2. Continued.

\begin{tabular}{|c|c|c|c|c|c|c|c|c|}
\hline \multicolumn{2}{|c|}{ The feature that is deteriorating } & Grouping & Significance & Anti weight & $\begin{array}{l}\text { Preliminary } \\
\text { anti-action }\end{array}$ & $\begin{array}{l}\text { Preliminary } \\
\text { action }\end{array}$ & Equipotentiality & Transfer \\
\hline \multicolumn{2}{|c|}{ The feature that is improving } & 7 & 8 & 9 & 10 & 11 & 12 & 13 \\
\hline \multirow{2}{*}{1} & \multirow{2}{*}{ Segmentation } & 292 & - & 28 & 810 & 1036 & 1014 & 135 \\
\hline & & 4028 & - & 1538 & 1837 & 3740 & 3540 & 1939 \\
\hline \multirow{2}{*}{2} & \multirow{2}{*}{ Taking out } & \multirow{2}{*}{-} & 535 & \multirow[b]{2}{*}{ - } & 810 & 1329 & 1310 & 2639 \\
\hline & & & 142 & & 1935 & 1018 & 2914 & 140 \\
\hline \multirow{2}{*}{3} & \multirow{2}{*}{ Local quality } & 717 & \multirow[b]{2}{*}{ - } & 134 & 1710 & 18 & 18 & 18 \\
\hline & & 435 & & 8 & & 35 & 1029 & 1534 \\
\hline \multirow{2}{*}{4} & \multirow{2}{*}{ Asymmetry } & \multirow{2}{*}{ - } & 358 & \multirow{2}{*}{-} & \multirow{2}{*}{2810} & 114 & 1314 & 3937 \\
\hline & & & 214 & & & 35 & 157 & 35 \\
\hline \multirow{2}{*}{5} & \multirow{2}{*}{ Merging } & 714 & \multirow[b]{2}{*}{ - } & 2930 & 1930 & 1015 & 534 & 112 \\
\hline & & 174 & & 434 & 352 & 3628 & 294 & 1339 \\
\hline 6 & Universality & - & - & - & $\begin{array}{l}118 \\
3536\end{array}$ & $\begin{array}{l}1015 \\
3637\end{array}$ & - & 238 \\
\hline \multirow{2}{*}{7} & \multirow{2}{*}{ Grouping } & & & 294 & 1535 & 635 & 115 & 2810 \\
\hline & & & - & 3834 & 3637 & 3637 & 294 & 139 \\
\hline 8 & & & & & 218 & 2435 & 72 & 3428 \\
\hline 8 & Significance & - & & - & 37 & 2435 & 35 & 3540 \\
\hline 9 & & 729 & - & & 1328 & 618 & 3515 & 2833 \\
\hline 9 & Ant1 weight & 34 & - & & 1519 & 3840 & 1834 & 118 \\
\hline & Doliming ontions & 159 & 236 & 1328 & & 1821 & 1035 & 3510 \\
\hline 10 & Preliminary anti-action & 1237 & 1837 & 1512 & & 11 & 4034 & 21 \\
\hline & & 635 & & 635 & 3635 & & 354 & 3533 \\
\hline 11 & Preliminary action & 10 & 3524 & 36 & 21 & & 1510 & 240 \\
\hline 12 & & 144 & 72 & 3515 & 3510 & 3415 & & 331 \\
\hline 12 & Equipotentiality & 1522 & 35 & 3418 & 3740 & 1014 & & 184 \\
\hline & & 2810 & 3428 & 3315 & 1035 & 235 & 221 & \\
\hline 13 & Transfer & 1939 & 3540 & 2818 & 2116 & 40 & 184 & \\
\hline 14 & Suberoidolity & 1015 & 914 & 813 & 1018 & 103 & 1030 & 1317 \\
\hline 14 & Spheroidality & 147 & 1715 & 2614 & 314 & 1840 & 3540 & 35 \\
\hline & & 102 & & 335 & 192 & 193 & 1426 & 133 \\
\hline 15 & Dynamics & 1930 & - & 5 & 16 & 27 & 2825 & 35 \\
\hline & & & 3534 & & & & & 393 \\
\hline 16 & Partial or excessive actions & - & 38 & - & - & - & - & 3523 \\
\hline & & 3439 & 356 & 228 & 3510 & 3539 & 1422 & 135 \\
\hline 17 & Transfer & 4018 & 4 & 3630 & 321 & 192 & 1932 & 32 \\
\hline & & 213 & & 1013 & 2619 & 列 & 3230 & 323 \\
\hline 18 & Frequency & 10 & - & 19 & 6 & - & 3230 & 27 \\
\hline 19 & & 3513 & & 835 & 1626 & 2314 & 122 & 1913 \\
\hline 19 & Periodic action & 18 & - & 35 & 212 & 25 & 29 & 1724 \\
\hline 20 & Continuity of useful action & - & - & - & 3637 & - & - & 274 \\
\hline
\end{tabular}

Tab. 2. Continued.

\begin{tabular}{|c|c|c|c|c|c|c|c|c|}
\hline \multicolumn{2}{|c|}{ The feature that is deteriorating } & Spheroidality & Dynamics & $\begin{array}{l}\text { Partial or } \\
\text { excessive actions }\end{array}$ & $\begin{array}{l}\text { Another } \\
\text { dimension }\end{array}$ & Frequency & $\begin{array}{l}\text { Periodic } \\
\text { action }\end{array}$ & $\begin{array}{l}\text { Continuity of } \\
\text { useful action }\end{array}$ \\
\hline \multicolumn{2}{|c|}{ The feature that is improving } & 14 & 15 & 16 & 17 & 18 & 19 & 20 \\
\hline \multirow{2}{*}{1} & \multirow{2}{*}{ Segmentation } & 2827 & 534 & & 629 & 191 & 3512 & \\
\hline & & 1840 & 3135 & - & 438 & 32 & 3431 & - \\
\hline \multirow{2}{*}{2} & \multirow{2}{*}{ Taking out } & 282 & & 227 & 2819 & 1932 & & 1819 \\
\hline & & 1027 & - & 196 & 3222 & 35 & - & 281 \\
\hline \multirow{2}{*}{3} & \multirow{2}{*}{ Local quality } & 835 & \multirow{2}{*}{19} & \multirow{2}{*}{ - } & 1015 & \multirow{2}{*}{32} & 835 & \multirow[b]{2}{*}{ - } \\
\hline & & 2934 & & & 19 & & 24 & \\
\hline \multirow{2}{*}{4} & \multirow{2}{*}{ Asymmetry } & 1514 & \multirow[b]{2}{*}{-} & 110 & 335 & \multirow{2}{*}{325} & \multirow[b]{2}{*}{-} & \multirow[b]{2}{*}{ - } \\
\hline & & 2826 & & 35 & 3818 & & & \\
\hline \multirow{2}{*}{5} & \multirow{2}{*}{ Merging } & 315 & \multirow{2}{*}{63} & \multirow{2}{*}{ - } & 215 & 1532 & \multirow{2}{*}{1932} & \multirow{2}{*}{-} \\
\hline & & 4014 & & & 16 & 1913 & & \\
\hline 6 & Universality & 40 & - & 210 & 3539 & - & - & - \\
\hline
\end{tabular}




\begin{tabular}{|c|c|c|c|c|c|c|c|c|}
\hline \multicolumn{2}{|c|}{ The feature that is deteriorating } & Spheroidality & Dynamics & $\begin{array}{l}\text { Partial or } \\
\text { excessive actions }\end{array}$ & $\begin{array}{l}\text { Another } \\
\text { dimension }\end{array}$ & Frequency & $\begin{array}{l}\text { Periodic } \\
\text { action }\end{array}$ & $\begin{array}{l}\text { Continuity of } \\
\text { useful action }\end{array}$ \\
\hline \multicolumn{2}{|c|}{ The feature that is improving } & 14 & 15 & 16 & 17 & 18 & 19 & 20 \\
\hline \multirow{3}{*}{7} & \multirow{3}{*}{ Grouping } & & & 1930 & 38 & & \multirow{3}{*}{35} & \multirow{3}{*}{-} \\
\hline & & 914 & 635 & \multirow{2}{*}{ - } & 3439 & 213 & & \\
\hline & & 157 & 4 & & 1018 & 10 & & \\
\hline \multirow{2}{*}{8} & \multirow{2}{*}{ Significance } & 914 & & 3534 & 356 & & \multirow{2}{*}{ - } & \multirow{2}{*}{-} \\
\hline & & 1715 & - & 38 & 4 & - & & \\
\hline \multirow{2}{*}{9} & \multirow{2}{*}{ Anti weight } & 83 & 319 & \multirow[b]{2}{*}{-} & 2830 & 1013 & 815 & \multirow[b]{2}{*}{-} \\
\hline & & 2614 & 355 & & 362 & 19 & 3538 & \\
\hline \multirow{2}{*}{10} & \multirow{2}{*}{ Preliminary anti-action } & 3510 & 102 & \multirow{2}{*}{-} & 3510 & \multirow{2}{*}{ - } & 1917 & 116 \\
\hline & & 1427 & 192 & & 21 & & 10 & 3637 \\
\hline \multirow{2}{*}{11} & \multirow{2}{*}{ Preliminary action } & 918 & 193 & \multirow{2}{*}{-} & 3539 & \multirow{2}{*}{-} & 1424 & \multirow{2}{*}{-} \\
\hline & & 340 & 27 & & 192 & & 1037 & \\
\hline \multirow{2}{*}{12} & \multirow{2}{*}{ Equipotentiality } & 3014 & 1426 & \multirow[b]{2}{*}{-} & 2214 & 1315 & 26 & \multirow[b]{2}{*}{-} \\
\hline & & 1040 & 925 & & 1932 & 32 & 3414 & \\
\hline \multirow{2}{*}{13} & \multirow{2}{*}{ Transfer } & 179 & 1327 & 393 & 351 & 323 & 1210 & 274 \\
\hline & & 15 & 1035 & 3523 & 32 & 2716 & 1319 & 2918 \\
\hline 14 & Snheroidality & & 273 & - & 3010 & 3510 & 1935 & 35 \\
\hline 14 & spneroidanty & & 26 & - & 40 & 3519 & 10 & 35 \\
\hline 15 & Dynamics & 273 & & & 1935 & 219 & 286 & \\
\hline 12 & Dynamics & 10 & & - & 39 & 435 & 3518 & - \\
\hline 16 & Partial or excessive actions & - & - & & $\begin{array}{l}1918 \\
3640\end{array}$ & - & - & - \\
\hline 17 & Trancfer & 1030 & 1913 & 1918 & & 3230 & 1915 & \\
\hline 17 & Iranster & 2240 & 39 & 3640 & & 2116 & 317 & - \\
\hline 18 & Frequency & & 219 & & 3235 & & 321 & 3235 \\
\hline 18 & Frequency & 3519 & 6 & - & & & 19 & 115 \\
\hline 10 & Periodic action & 519 & 2835 & & 1924 & 215 & & \\
\hline 19 & Periodic action & 935 & 618 & - & 314 & 19 & & - \\
\hline 20 & Continuity of useful action & 35 & - & - & - & 192 & - & \\
\hline
\end{tabular}

Tab. 3. Innovative principles in education - description and actions.

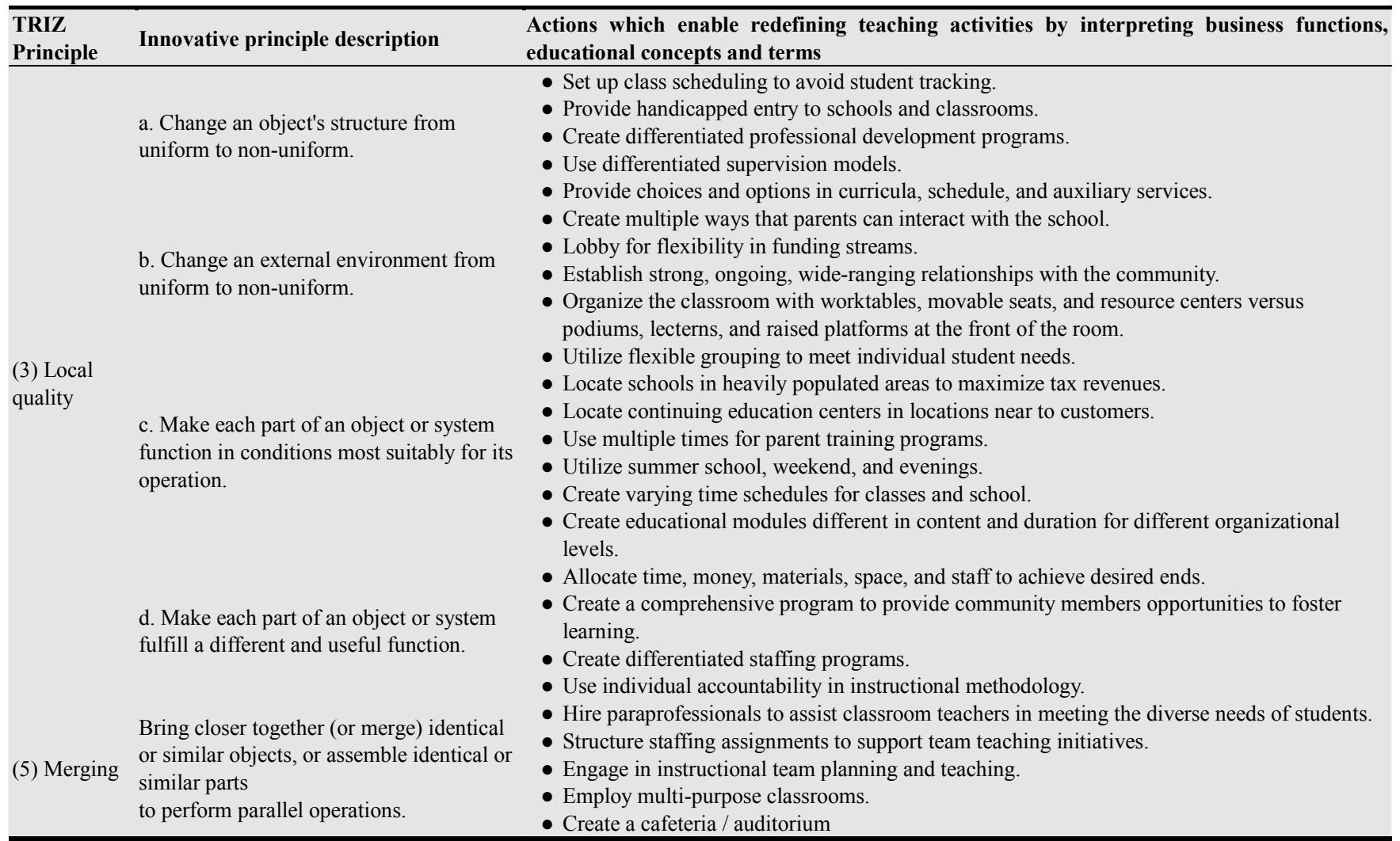




\begin{tabular}{lll}
\hline $\begin{array}{l}\text { TRIZ } \\
\text { Principle }\end{array}$ & Innovative principle description & $\begin{array}{l}\text { Actions which enable redefining teaching activities by interpreting business functions, } \\
\text { educational concepts and terms }\end{array}$ \\
\hline & - In universities and private schools locate the Registrar and Bursar offices close together. \\
- Encourage collaboration between teachers and parents. \\
- Organize action research groups to study influences, practices, and results of curriculum \\
- design. \\
- Combine skill based experiences within fundraiser activities. \\
- Use team teaching to capitalize on teacher expertise. \\
- Create inclusive classrooms with a co-teaching structure. \\
Make objects or operations contiguous or & - Coordinate library and media centers. \\
parallel; bring them together in time. & - Incorporate interdisciplinary curricula and instruction. \\
& - Offer internships, shadowing, and cooperative education opportunities. \\
& - Locate computers in classrooms. \\
\hline
\end{tabular}

There are many various ways of using contradiction matrix. On one end of that spectrum of users are those who want to use all 40 innovative principles, while at the other end of the spectrum are those users who focus on lesser number of innovative principles "probably represented" in the course of analyzing problems and finding solutions. During analysis of various solutions, practical experiences and various ways of usage, the contradiction matrix has suffered numerous changes aimed at finding those principles which are most probably represented, so that the 2003 contradiction matrix originated [5]. The goal of this more flexible usage of innovative principles is further research of contradiction matrix stability and obtaining quantified data about whether innovative principles have been well established.

The sequence of the most probably represented innovative principles in classical contradiction matrix is shown in the second column of Tab. 4/, while their sequence of occurrence in the 2003 contradiction matrix is shown in the third column of Tab. 4. [5].

Tab. 4. Comparison of innovative principles of classical and 2003 contradiction matrixes.

\begin{tabular}{|c|c|c|c|c|}
\hline $\begin{array}{l}\text { Innovative principles } \\
\text { ordinal number principa }\end{array}$ & Name of innovative principle & $\begin{array}{l}\text { Classical contradiction } \\
\text { matrix - rank }\end{array}$ & $\begin{array}{l}2003 \text { contradiction matrix - } \\
\text { rank }\end{array}$ & Change of sequence \\
\hline 1 & Segmentation & 3 & 7 & -4 \\
\hline 2 & Taking out & 5 & 5 & 0 \\
\hline 3 & Local quality & 12 & 2 & 10 \\
\hline 4 & Asymetry & 24 & 10 & 14 \\
\hline 5 & Merging & 33 & 12 & 21 \\
\hline 7 & Grouping & 34 & 17 & 17 \\
\hline 8 & Significance & 32 & 37 & -5 \\
\hline 9 & Preliminary anti-action protivdejstva & 39 & 24 & 15 \\
\hline 10 & Preliminary actions & 2 & 8 & -6 \\
\hline 11 & Beforehand cushioning & 29 & 39 & -10 \\
\hline 12 & Equipotentiality & 37 & 19 & 18 \\
\hline 14 & Spheroidality & 21 & 15 & 6 \\
\hline 15 & Dynamics & 6 & 14 & -8 \\
\hline 16 & Partial or excessive actions & 16 & 28 & -12 \\
\hline 17 & Transition to Another dimension & 19 & 9 & 10 \\
\hline 18 & Vibrations & 8 & 25 & -17 \\
\hline 19 & Periodic action & 7 & 11 & -4 \\
\hline 20 & Continuity of useful action & 40 & 40 & 0 \\
\hline 21 & Skipping & 35 & 32 & 3 \\
\hline 22 & Blessing in disguise & 22 & 36 & -14 \\
\hline 23 & Feedback & 36 & 33 & 3 \\
\hline 24 & Intermediary & 18 & 6 & 12 \\
\hline 25 & Self-service & 28 & 13 & 15 \\
\hline 26 & Copying & 11 & 23 & -12 \\
\hline 27 & Cheap short-lived objects & 13 & 35 & -22 \\
\hline 30 & Flexible shells and thin films & 25 & 22 & 3 \\
\hline 31 & Porous materials & 30 & 16 & 14 \\
\hline 32 & Colour changes & 9 & 21 & -12 \\
\hline 33 & Homogeneity & 38 & 38 & 0 \\
\hline
\end{tabular}




\begin{tabular}{lllll}
\hline $\begin{array}{l}\text { Innovative principles } \\
\text { ordinal number principa }\end{array}$ & Name of innovative principle & $\begin{array}{l}\text { Classical contradiction } \\
\text { matrix - rank }\end{array}$ & $\begin{array}{l}\text { 2003 contradiction matrix - } \\
\text { rank }\end{array}$ & Change of sequence \\
\hline 34 & Discarding and recovering & 15 & 31 & -16 \\
35 & Parameter changes & 1 & 1 & 0 \\
36 & Phase transitions & 27 & 30 & -3 \\
37 & Thermal expansion & 26 & 20 & 6 \\
38 & Strong oxidants & 31 & 34 & -3 \\
& Inert atmosphere & 23 & 29 & -6 \\
40 & Composite materials & 17 & 18 & -1 \\
\hline
\end{tabular}

It can be seen that change of place has occurred in most innovative principles with respect to the type of matrix. Any interpretation of the difference that has occurred as the "most probably represented" innovative principle inevitably contains a certain degree of uncertainty. However, consideration of these changes is valid because it contains direct comparison of what was done in developing the TRIZ method in the period from 1950-ies to 1980-ies, with respect to the method's results after 1985-ies of the previous century, (4).

The highest rise, as can be seen, has happened to the following innovative principles, in the ordinal way: $5,12,7$, $25,9,31,24,3,17,13$. It is therefore very important to state that that innovative characteristic number 5 - Merging has been the top "rebel" and winner. This leads to the conclusion that creative ideas have most often led to solving the problem complexity by using the strategies of reducing system complexity by merging the system parts, (Fig. 4). At the same time, this means that problem solutions are directed towards a higher degree of system integration. Also, merging can be understood as increased effect of tools on the way of thinking about the system. It is possible that using of most complex tools was prematurely attributed to TRIZ method, aimed at reducing time of merging parts in the system, so that it is worth mentioning the increase in the frequency of occurrence of the innovative principle 5 - Merging.

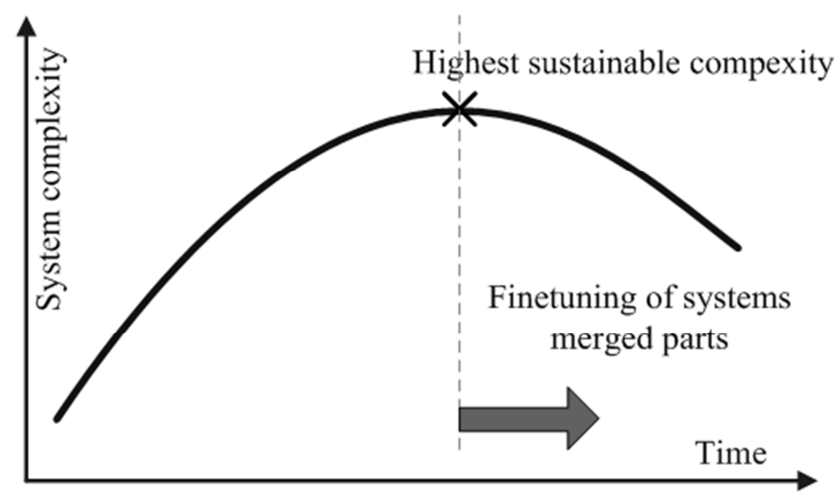

Fig. 4. System complexity and connection with the innovative principle $5-$ Merging.

The next innovative principle which rose in frequency of occurrence is number 25 - Self-service. This is in accordance with the development of TRIZ method directed towards better usage of existing system resources and the attempt to submit useful system functions "about itself". Increased frequency of this principle is in accordance with the system's self service which uses the TRIZ methods.
One of the innovative principles which also had significant rise is the principle 17 - Transition to other dimensions, as the dimension of the TRIZ inventive strategy.

The greatest downturn has occurred with the following innovative principles, given by sequence: $27,18,34,22,16$, 26, 29, 32, 11, 15 .

By definition, number of principles in increase of frequence must be identical to adequate numbe of principles in downturn. It should be mentioned here that the innovative principle 27 - Cheep -short lived objects has had the largest downfall in the 2003 contradiction matrix with respect to the classical contradiction matrix. It is reasonable to ask if this change has occurred due to shortcomings in the classical contradiction matrix. The most probable answer to this would be that this downfall in correlation with the rising trend of sustainable solutions, on the one hand, while on the other hand, there is increase of frequency of "cheep" education in certain regions in the world. In other words, the innovative principle 27 can and should have high frequency of occurrence, but legislation in those countries is less based on strategy, so the principle is rarely present there as the problem solution. Similar arguments can be related to the downfall of frequency and significance of the innovative principles: 22-Blessing in disguise and 34- Discarding and recovering, i.e. it means that these principles have got the same frequency of occurrence as before, but the empiric experience has shown that among the innovative principles experiencing downfall, the principle number 15 - Dynamics should be mentioned as particularly interesting. Careful analysis of possible reasons points towards the following reasons:

- abrupt participation increase of electronics, software and bio-sciences has influenced this principle's low frequency, where the frequency is expressed more at system designing as part of the innovative strategy, than it appears to be represented in software or bio-sciences applications. In the system itself, the principle $15-$ Dynamics is the concept usually reviewed as something automatically set, not requiring usage of innovative solution levels.

- increased usage of electronic means is evident, such as, for example, "wireless control", "sensor control". The TRIZ trend of increased system dynamics is shown in Fig. 5, pointing towards composing of the system as a set of basic systems. Here lies the cause of fall in frequency of the innovative principle 29 - Pneumatics 
and hydraulics in the 2003 matrix.

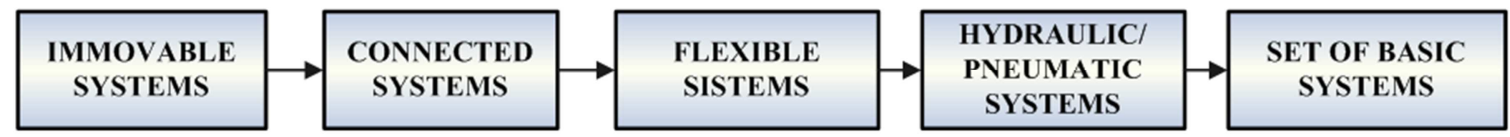

Fig. 5. TRIZ dynamization trend.

The drop of the innovative principle number 11Beforehand cushioning should also be mentioned, with the simultaneous rise of the innovative principle 9 - Preliminary anti-action, which can be related to frequent occurrence of system network modeling and the increasingly used technique of risk assessment, so that very often, in analyzing system behavior, it is not necessary to include feedback effects.

This thinking is also in accordance with the previous one, with the increase of innovative principle 5 - Merging, as the part of inventive strategy.

\section{Conclusion}

The paper considers application of the TRIZ method through proposing different principles of decision making and qualitative estimation. The contradictions stated in the analysis of the process of education so far, and of planning and implementation of new teaching programs into the educational system are generally solved by searching for compromise solutions. Implementation of the TRIZ method implies increase of creativity through the process of bringing compromised solutions, by including the ideas from the theories of complexity and cybernetics into the philosophy basis, by the use of contradiction matrix.

Contradictions prove, on the basis of analyzing the education field regulations and safety and experiences during educational system functioning, that creativity is more than art. It is estimated that application of the classical TRIZ method principles is becoming necessary but not sufficient if it is to become a part of a "systematic education development for a creative discussion". Matrix 2003 represents advance with respect to the classical one, taking into consideration the frequencies of occurrence of innovative principles, where the order has been confirmed of innovative principles $35,28,10$, 1 and 2 both in classical contradiction matrix and in 2003 matrix. On the other hand, certain discrepancies have occurred in the representation sequence of innovative principles.

To the experts who in problem solving do not pay special attention to contradiction details in defining contradiction but who use innovative principles in problem solving, the 2003 matrix offers the revised list of the "most probably represented" innovative principles. It is necessary to point to the fact that using the term "most probably" inevitably leads to exempting of much relevant information.

It is believed that it would be suitable to introduce the TRIZ method in resolving problems in secondary/grammar schools, as the thematic content of the training. As regards the level of education at which introducing TRIZ training should be commenced, the ages of the $2^{\text {nd }}$ and $3^{\text {rd }}$ secondary grades are considered as the optimum. In the Ministry of Education and Science, possibilities are considered, and feasibility studies conducted, for discovering, applying and supporting creativity. The authors have gained experience in TRIZ-education and have used numerous experiences from teaching.

The focal point of future research should be searching of a new matrix which will contain certain probability of the "best" innovative principle occurrence and its influence on the searched for solution.

\section{References}

[1] Stefanović, N., Mitrović, R., Popović, P., Innovative problem solving methods in education field, Published online February 20, 2013 (http://www.sciencepublishinggroup.com/j/edu), Science Pubilishing Group, Science PG

[2] Altshuller G. S., (1946-1971) Теория Решеня Изобретательных Задач - ТРИЗ, Innovation Algorithm. Worcester, Massachusetts,

[3] Altshuller G., S. And Suddenly the Inventor Appeared: TRIZ, the Theory of Inventive Problem Solving, Paperback $2^{\text {nd }}$ edition, May 1996, Technical Innovation Center; ISBN: 0964074028 .

[4] Kaplan L., Malkin S., Proseanic V., Visnepolschi S., Zlotin, A., Zusman A., (2001), TRIZ beyond technology“", The theory and practice of applying TRIZ to nontechnical areas.

[5] Mann, D. L., Dewulf, S., Zlotin, B., Zusman, A., 'Matrix 2003: Updating The TRIZ Contradiction Matrix', CREAX Press, July 2003.

[6] Mann, D., Marsh, D., Waters, F., (2002) ,Using TRIZ to Resolve Educational Delivery Conflicts Inherent to Expelled Students in Pennsylvania“, November 2002.

[7] Rea, K., 'Applying TRIZ to Software Problems', TRIZ Journal, October 2002.

[8] Stefanović N., (2010) Ph. D. thesis, Model of assessing risk of IT systems, Novi Sad, Faculty for economics and engineer management.

[9] Souchkov V., "Accelerate Innovation with TRIZ" 1997, revised in 2010, ICG Training and consulting

[10] Terninko, J., 'Inventive Principles with Social Examples', The TRIZ Journal, www.trizjournal.com., June 2001.

[11] Zlotin, Boris and Alla Zusman. The Inventor Came to Class. Kishinev: Kartya Moldovenyaska Publishing House, 1990. 